\title{
Can Exposure to Celebrities Reduce Prejudice? The Effect of Mohamed Salah on Islamophobic Behaviors and Attitudes
}

\author{
ALA' ALRABABA'H Stanford University \\ WILLIAM MARBLE Stanford University \\ SALMA MOUSA Yale University \\ ALEXANDRA A. SIEGEL University of Colorado Boulder
}

\begin{abstract}
C
an exposure to celebrities from stigmatized groups reduce prejudice? To address this question, we study the case of Mohamed Salah, a visibly Muslim, elite soccer player. Using data on hate crime reports throughout England and 15 million tweets from British soccer fans, we find that after Salah joined Liverpool F.C., hate crimes in the Liverpool area dropped by 16\% compared with a synthetic control, and Liverpool F.C. fans halved their rates of posting anti-Muslim tweets relative to fans of other top-flight clubs. An original survey experiment suggests that the salience of Salah's Muslim identity enabled positive feelings toward Salah to generalize to Muslims more broadly. Our findings provide support for the parasocial contact hypothesis-indicating that positive exposure to out-group celebrities can spark real-world behavioral changes in prejudice.
\end{abstract}

I n February 2018, fans of one of England's most storied soccer clubs, Liverpool F.C., celebrated a decisive victory in soccer's most elite league. A 5-0 win over F.C. Porto in the U.E.F.A. Champions League previewed an excellent season that saw Liverpool F.C. advance to the final. Mohamed Salah, a young Egyptian striker, was key to the club's success. After the victory, fans chanted:

If he scores another few

Then I'll be Muslim, too.

If he's good enough for you,

He's good enough for me.

Sitting in a mosque,

That's where I wanna be.

Fans created more homespun chants as Liverpool F.C. continued their successful season:
Mohamed Salah
A gift from Allah.
He's always scoring,
It's almost boring.
So please don't take
Mohamed away.

\begin{abstract}
Ala' Alrababa'h (D), Ph.D. Candidate, Department of Political Science, Stanford University, and Immigration Policy Lab, Stanford University and ETH Zurich, alaa@stanford.edu.

William Marble (D), Ph.D. Candidate, Department of Political Science, Stanford University, wpmarble@stanford.edu.

Salma Mousa (D), Assistant Professor, Department of Political Science, Yale University, sm3285@yale.edu.

Alexandra A. Siegel (ID), Assistant Professor, Department of Political Science, University of Colorado Boulder, and Immigration Policy Lab, Stanford University and ETH Zurich, alexandra.siegel@colorado.edu.
\end{abstract}

Received: July 16, 2019; revised: March 31, 2021; accepted: May 03, 2021. First published online: June 07, 2021.
In the first three seasons that Salah played for Liverpool F.C., the club was extraordinarily successful, appearing in consecutive U.E.F.A. Champion's League finals and taking the title in 2019. The club was similarly successful in the domestic league, winning the English Premier League for the first time in club history in 2020 , with Salah being crowned the league's top goal scorer two years in a row.

Salah is noteworthy not only for his skill on the soccer field, but also for his conspicuous Islamic identitywhich was arguably unprecedented in elite soccer. European fans were not accustomed to seeing players prostrate to perform a Muslim prayer (sujood) after scoring goals, for example. His popularity fueled media speculation that Salah's Muslim identity might be reducing Islamophobia among fans (The National 2018; Thomas 2018)..$^{1}$ Some pundits argued that Salah portrayed "favorable images of Muslims, helping to reduce stereotypes and break down barriers within communities" (Monks 2018). Others disagreed. Despite the fact that "everyone loves a winner," there was still no systematic evidence that Salah's fame could "in any way decrease the mainstream Islamophobia in British culture" (Al-Sayyad 2018). Beyond anecdotes, little is known about whether Salah has had a systematic influence on Islamophobia.

The possibility that exposure to Salah reduced Islamophobia supports the parasocial contact hypothesis (Schiappa, Gregg, and Hewes 2005) - the idea that mediated contact with celebrities or characters from out-groups has the potential to reduce prejudice toward the out-group as a whole. This proposed extension to Allport's (1954) classic contact hypothesis has received support in observational studies as well as

\footnotetext{
${ }^{1}$ We adopt a relatively expansive definition of Islamophobia: fear, hatred, or dislike of Islam or Muslims, as well as anti-Muslim prejudicial attitudes or behaviors more generally (Sheridan 2006).
} 
laboratory- and survey-based experiments, but not in naturalistic settings with causal purchase. In this paper, we provide a real-world test of the parasocial contact hypothesis. We test the proposition that Salah's meteoric rise reduced anti-Muslim attitudes and behaviors among Liverpool F.C. fans. We test this hypothesis using three complementary research designs: an analysis of hate crimes in England, an analysis of anti-Muslim tweets among U.K. soccer fans, and an original survey experiment.

First, we draw on hate crime data from 25 police departments in England between 2015 and 2018. We employ a variant of the synthetic control method to generate a counterfactual hate crime rate for the Merseyside police force - which covers the city of Liverpool-after Salah signed with Liverpool F.C. We find that Merseyside experienced a $16 \%$ lower hate crime rate after Salah was signed relative to the expected rate had he not been signed. Second, we analyze 15 million tweets produced by followers of prominent soccer clubs in the English Premier League. Using the same synthetic control method as in our hate crime analysis, we find that the proportion of anti-Muslim tweets produced by Liverpool F.C. fans after Salah joined was about half of the expected rate had he not joined the club $-3.8 \%$ versus $7.3 \%$ of tweets related to Muslims. Finally, we implement a survey experiment among 8,060 Liverpool F.C. fans to explicitly test how exposure to Salah might lead to generalized tolerance toward Muslims. In line with the parasocial contact hypothesis, our results suggest that the salience of Salah's Muslim identity reduced prejudice toward Muslims writ large. Priming respondents with information about Salah's religious practices boosted the belief that Islam is compatible with British values by around 5 percentage points, compared to the baseline rate of $18 \%$ among the control group. These findings suggest that positive exposure to out-group celebrities, especially when these celebrities' minority group membership is highly salient, can reduce prejudice.

This "Salah effect" is likely not unique to Salah. Celebrities with role model-like qualities have long been thought to shape social attitudes. When Jackie Robinson broke baseball's color barrier in 1947, his "efforts were a monumental step in the civil-rights revolution in America ... [His] accomplishments allowed black and white Americans to be more respectful and open to one another," according to historian Doris Kearns Goodwin (Williams and Sielski 2004, 212). British-Bangladeshi Nadiyah Hussain, the headscarf-clad winner of the most watched program on British television, The Great British Bake-Off, was credited with doing "more for British-Muslim relations than 10 years of government policy" after her 2015 win (Wiseman 2018). The 2018 reboot of Queer Eye for the Straight Guy has similarly been lauded as a "tool for helping people unlearn" homophobia (Reyes 2018).

Exposure to celebrities through mass media is one of the most common forms of intergroup contact, making parasocial contact an important but understudied frontier of prejudice reduction research (Park 2012).
This study contributes to our understanding of parasocial contact in four primary ways. First, we study naturally occurring exposure to a celebrity-rather than exposure induced in a laboratory or survey experimentproviding strong claims to external validity. Second, we examine an unexpected and plausibly exogenous increase in exposure to a celebrity from a minority group, allowing us to estimate plausible counterfactuals. This research design gives us causal purchase beyond what is typically attainable in observational studies of parasocial contact or the contact hypothesis more generally, where selection bias (more tolerant individuals selecting into intergroup contact) poses a threat to inference. Third, we study behavioral outcomes, including hate crimes and hate speech, that are of direct relevance for policy. Finally, we buttress our observational results with an original survey experiment. This lends further credence to our causal estimates and tests a critical assumption needed for parasocial contact with one individual to reduce prejudice toward an entire group: the salience of group identity.

The rest of the paper is structured as follows. In the next section, we draw on the parasocial contact literature to motivate our empirical hypotheses. Next, we provide a brief discussion of Islamophobia in the U.K. Then, we present our analysis of hate crime data in England, which is followed by an analysis of tweets produced by Twitter followers of English Premier League clubs. After a brief discussion of robustness and generalizability, we describe our original survey experiment testing the proposition that the salience of Salah's identity may play a key role in reducing prejudice toward Muslims more generally. In the discussion section, we interpret the results and address their generalizability before concluding the paper.

\section{THE PARASOCIAL CONTACT HYPOTHESIS}

A rich literature documents the relationship between various forms of intergroup contact and prejudice. The contact hypothesis posits that personal contact across social lines can reduce prejudice if that contact is positive, endorsed by communal authorities, egalitarian, and involves cooperating to achieve a common goal (Allport 1954). Such contact has been found to reduce prejudice by alleviating intergroup anxieties, inducing empathy, highlighting commonalities, and forging friendships, among other social, emotional, and cognitive pathways (Pettigrew 1998; Pettigrew and Tropp 2006). Experimental evidence from myriad contexts and countries establishes the effectiveness of positive contact in improving intergroup relations (Barnhardt 2009; Burns, Corno, and La Ferrara 2015; Carrell, Hoekstra, and West 2015; Lowe 2017; Rao 2019). Meta-analyses subsequently conclude that positive contact "typically reduces prejudice" (Paluck, Green, and Green 2019; Pettigrew and Tropp 2006).

While intergroup contact presents a promising way to foster tolerance, its potential may be limited by a lack of opportunities for such contact. Residential and occupational segregation, intergroup anxiety, or the small 
size of some minority groups can pose social, economic, and psychological barriers to meaningful intergroup contact (Enos 2017; Joyce and Harwood 2014; Ortiz and Harwood 2007). This has led scholars, including the father of the contact hypothesis, to suggest that mass media may play an important role in shaping and sustaining prejudice (Allport 1954).

Building on this insight, Schiappa, Gregg, and Hewes (2005) propose the "parasocial contact hypothesis" as an analogue of the classic contact hypothesis. This hypothesis stipulates that mediated contact with members of minority groups has the potential to reduce prejudice toward that group. Numerous observational and experimental laboratory studies document support for the parasocial contact hypothesis. While much of this literature has focused on the role of negative media coverage in exacerbating prejudice (Ramasubramanian 2013), exposure to fictional television characters and celebrities has also been shown to reduce racial prejudice, religious prejudice, prejudice based on gender or sexual orientation, and prejudice against individuals with disabilities and mental health disorders (Abrams, McGaughey, and Haghighat 2018; Bond 2020; Miller et al. 2020; Park 2012; Wong, Lookadoo, and Nisbett 2017).

Like face-to-face contact, the quality and quantity of parasocial contact determines the degree to which it reduces prejudice. While the conditions under which parasocial contact might be successful have yet to be systematically tested, Schiappa, Gregg, and Hewes (2005) propose that parasocial contact should involve repeated exposure to individuals who are both likable and clearly identifiable as members of an out-group. Studies of traditional intergroup contact similarly highlight the importance of repeated exposure (Dovidio et al. 2017), a positive experience (Aberson 2015; Barlow et al. 2012; Paolini, Harwood, and Rubin 2010), and a salient out-group identity (Al Ramiah and Hewstone 2013). When these conditions are met, individuals appear to use the same cognitive processes underpinning prejudice reduction during parasocial contact-for example, in developing "relationships" with television characters-as they do in real-world intergroup contact (Park 2012).

For Liverpool F.C. fans during the study period, exposure to Salah fulfills these three criteria. First, fans have had sustained contact with Salah over time. Salah was a regular starter for Liverpool F.C.'s games within the English Premier League, which entails 38 weeks of game play every season in addition to appearances in other domestic and international tournaments. Off the field, Salah was active on social media and appeared in high-profile advertisements for corporations like Pepsi, Adidas, and Vodafone. Appearances in sporting events, sports television, and commercials are all known to facilitate parasocial relationships between fans and celebrity athletes (Brown and Basil 1995).

Second, with Salah enjoying tremendous success at the individual, club, and national levels during the study period, Salah was portrayed positively in the media and received a great deal of positive attention from fans and teammates. In May 2018, he carried his club to the world's most-watched annual sporting event, the U.E.F.A. Champions League Final, before leading the Egyptian national side to the F.I.F.A. World Cup for the first time in three decades one month later. His remarkable breakout season earned him a nomination for the English Premier League's Player of the Year and the coveted F.I.F.A. Puskás Prize for Goal of the Year, satisfying the positive exposure criterion of parasocial contact.

Finally, Salah's Muslim identity is highly salient. His first name is recognizably Muslim, he prostrates in prayer after scoring a goal, and points his index finger to the sky while reciting the shahada, the Muslim profession of faith. Die-hard fans will also know that Salah's daughter, Makka, is named after Islam's most sacred site, and his veiled wife can often be seen cheering him on from the sidelines. Salah is distinctive in this way: Europe has seen many excellent players of Muslim heritage, but most are dissociated from Islam in the minds of fans because of their lack of public piety. By contrast, fan chants centered on Salah refer to mosques, Muslims, and Allah while the Liverpool F.C. coach, Jürgen Klopp, has also pointed to Salah's religiosity as an integral part of his identity (Bascombe 2019). Given that Salah meets the three hypothesized criteria for parasocial contact to reduce prejudicepositivity, repeated exposure, and salient out-group identity - he provides an ideal case to test the parasocial contact hypothesis.

\section{CONTEXT: ISLAMOPHOBIA IN THE U.K.}

The British Empire has historically perpetuated racism to justify the continued occupation of foreign territories. South Asians and Afro-Caribbeans have subsequently endured a legacy of discriminatory policies and practices, including waves of violence by far-right, anti-immigrant groups. The government passed the Race Relations Acts of 1965 and 1976, and selfreported racist attitudes declined between the 1980s and 2001 (BBC News 2014). However, the terrorist attacks on September 11, 2001, and July 7, 2005, reinvigorated discrimination against visible minorities, particularly Muslims. Suspicion toward Muslims manifested in the behavior of the British state, media coverage of Muslims, and public attitudes toward Islam. Scholars have argued that British surveillance of Muslims following terrorist attacks was driven in large part by an irrational fear of Muslims and "informed by the framing of the terror threat as an Islamic threat, which casts all Muslims as potential terrorists that need to be monitored and categorised" (Qurashi 2018, 11). The sweeping skepticism toward Muslims ingrained in the British state bureaucracy was such that even Christians from Muslim-majority countries faced additional barriers during immigration and asylum processes (Madziva 2018).

The British media has also played a role in perpetuating a fear of Muslims and Islam. For instance, in response to a question by the Evening Standard about the effect of Islam on life in London, a former $B B C$ 
Today program editor asserted that "Islam is masochistic, homophobic and a totalitarian regime. It is a fascistic, bigoted and medieval religion" (Milly and Khiabany 2010, 86). A columnist for The Daily Mail characterized the veil worn by some Muslim women as an "Islamist symbol which plays a role analogous to the use of the swastika by Nazism" (Milly and Khiabany 2010, 87). Meanwhile, The Daily Express published a column that stated, "Make no mistake, the proliferation of the burka-wearing is a direct threat to the British way of life and in all too many instances is intended to be just that" (Milly and Khiabany 2010, 87). A study of the print news media between 2000 and 2008 found that $36 \%$ of stories about British Muslims overall are related to terrorism, with $32 \%$ of all stories about Muslims in 2008 centered on the religious and cultural differences between Islam and British values (Moore, Mason, and Lewis 2008). The rise of negative portrayals of Muslims in mainstream media has been accompanied by an increase in anti-Muslim cyber bullying, cyber harassment, cyber incitement, and threats of offline violence (Awan and Zempi 2016).

Negative attitudes toward Islam are similarly reflected in public opinion data. Figure 1 summarizes polling data, from YouGov, which shows a steady increase in the belief that "there is a fundamental clash between Islam and the values of British society" from 2015 to 2017. Despite a slight dip in 2017, over half of respondents continued to affirm this sentiment in 2018, signaling the persistence of skepticism toward Islam in the U.K.
High levels of prejudice compound other disadvantages faced by British Muslims. Data from the 2014 Office for National Statistics' Labour Force survey show that Muslim men are up to $76 \%$ less likely to be employed, and Muslim women up to six times less likely, than their white, non-Muslim counterparts (Khattab and Johnston 2015). A government report concluding that "Muslims experience the greatest economic disadvantages of any group in U.K. society" attributed part of this disadvantage to discrimination in the workplace (Stevenson et al. 2017). Discrimination also extends beyond the labor market. Over a quarter of British Pakistanis feel discriminated against on the housing market compared with just $1 \%$ of white non-Muslim Britons, according to a 2013 survey, and Muslims consistently report poorer health outcomes relative to other religious groups (Elahi and Khan 2017; McLeod 2013). Prejudice against Muslims also seems to beget violence. While race or ethnicity already motivated $82 \%$ of hate crimes in England and Wales in 2012 (Home Office 2012), reported abuse against Muslims nearly doubled between 2015 and 2017 according to one watch group (Tell Mama 2017).

How might parasocial contact operate in the British context? Prior work shows that the macropolitical environment and the tone of media coverage shape the outcomes of intergroup encounters, but that these effects are highly contextual. Hopkins (2010) finds that hostile national rhetoric, especially when combined with local demographic change, increases individual and political hostility toward ethnic out-groups. In contrast, Sønderskov, Mannemar, and Thomsen

\section{FIGURE 1. Attitudes toward Islam in the British Public between 2015 and 2018}

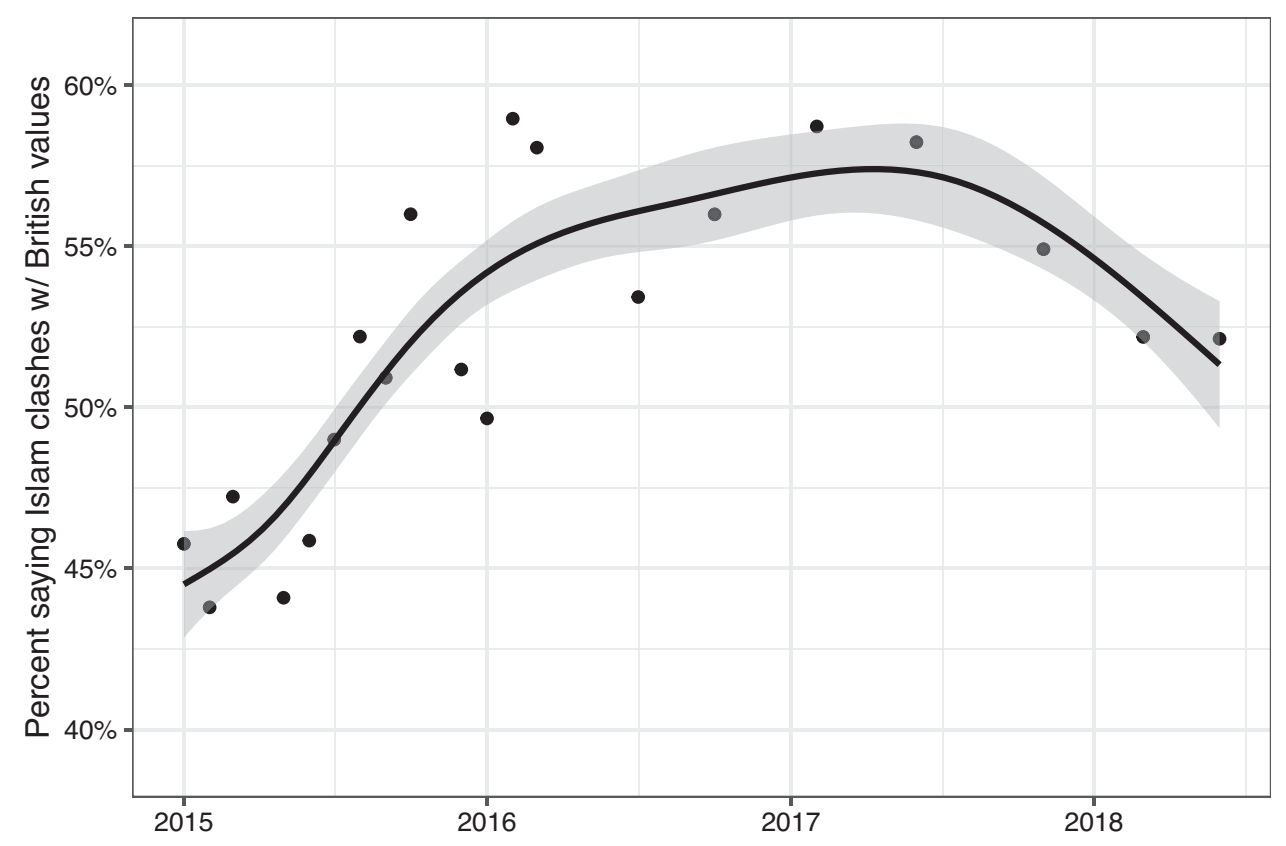

Note: Source: The YouGov-Cambridge Center. The vertical axis is the percentage of survey respondents stating that "there is a fundamental clash between Islam and the values of British society." Points are weighted averages within survey waves; the trend line is a GAM fit to all 34,409 survey respondents using survey weights. 
(2015) show that hostile national rhetoric can reduce prejudice among individuals with friends and coworkers from out-groups, further suggesting differential effects of national climates on prejudice.

Ex ante, it is not clear how intergroup contact might operate in the city of Liverpool. On one hand, Liverpool is less ethnically diverse than the rest of England (86.2\% white vs. the national average of $81.4 \%$ ) and is located in one of the top five police jurisdictions for hate crimes (Liverpool City Council 2011). On the other hand, Liverpudlians have long boycotted The Sun, one of the most influential right-wing tabloids, and therefore have more liberal attitudes on some political issues (Foos and Bischof 2018). Further complicating our expectations, the study period coincides with a Brexit process fueled by anti-immigrant sentiment (Goodwin and Milazzo 2017 ), but one that was ultimately rejected by $58.2 \%$ of Liverpool residents (BBC 2016). The complex interaction of individual, local, and national forces thus leaves us with ambiguous expectations with respect to the moderating effect of the political climate on intergroup contact in Liverpool during the study period.

\section{ANALYSIS OF HATE CRIMES IN THE U.K.}

We begin our empirical analysis with a hard test of the parasocial contact hypothesis: an analysis of hate crimes in the U.K. If Salah's signing decreased the general public's tolerance of hate crimes, or changed the underlying beliefs of bigots who commit hate crimes, then we would expect to see fewer hate crimes. ${ }^{2}$ To test this proposition, we use an event-study analysis that exploits Salah's rapid rise to fame. We analyze the hate crime rate in the Merseyside police force jurisdiction after Salah joined Liverpool F.C. and compare this rate with what we would have expected if prior trends had continued. We draw on hate crime statistics from over two dozen police forces in the U.K. to construct a synthetic control unit for Merseyside. We then compare the actual hate crime rate to the synthetic control as an estimate of the effect of Salah. We find that hate crimes in Merseyside were significantly lower after Salah joined Liverpool F.C. than we would have otherwise expected.

\section{Data and Research Design}

We gathered data on hate crimes by submitting Freedom of Information requests to every police department in England in April 2018. Police classify an incident as a hate crime when they have clear indication that the perpetrator targeted the victim mainly on the basis of their religious, racial, sexual, or abilities-based identity. We include a police jurisdiction in our analysis

\footnotetext{
${ }^{2}$ Hate crimes are rare events that are likely to be perpetrated by extreme bigots. Hate crimes are also public acts, and as such they are likely to be subject to social pressure. A reduction in hate crimes thus requires either that the underlying beliefs of these bigots have changed or that hate crimes are less socially acceptable.
}

if its response to our request was sufficient to calculate the total number of hate crimes reported in the jurisdiction for each month. We obtained usable data from 25 police jurisdictions out of the 39 contacted for a total of 936 police force-month observations.

Our main outcome is an annualized hate crime rate per thousand residents. For instance, a police jurisdiction with a population of 100,000 that experiences 10 hate crimes in a given month has an annual hate crime rate of $(10 / 100,000) \times 1,000 \times 12=1.2$ hate crimes per thousand residents in that month. ${ }^{3}$ The dependent variable ranges from 0 to a maximum of 4.342 , with a mean of 0.951 and standard deviation of 0.767 .

We consider the Merseyside police force-which covers Liverpool - to be treated after Salah's official signing in June 2017. ${ }^{4}$ When Salah joined, his transfer fee constituted a club record, stoking interest in the player among the club's fans and suggesting that his signing date is an appropriate choice for the start of the treatment. ${ }^{5}$ We present descriptive statistics and further discussion of the data in Appendix A.1.

Our goal is to estimate how hate crimes in Merseyside changed after Salah joined Liverpool F.C. relative to what would have happened had he not joined the team. This task requires estimating a counterfactual quantity: the trajectory of hate crimes in Merseyside had Salah not joined Liverpool F.C. To construct such a counterfactual, we use the pretreatment data from Merseyside and the control group data. Our main analysis uses the matrix completion method of Athey et al. (2021), as implemented in the R package gsynth (Xu and Liu 2018). This method imputes the unobserved outcomes in the posttreatment period by first looking for structure in the pretreatment control data that generates good predictions of the treated unit's outcomes in the pretreatment period. The same structure is then applied to the posttreatment periods to generate estimates of the counterfactual potential outcomes for the treated unit. To obtain an estimate of the treatment effect on the treated unit, we simply take the difference between the observed outcome for the treated unit in the posttreatment period and the imputed counterfactual outcome. ${ }^{6}$

Statistical inference in the setting of a single treated unit is challenging. Standard methods for computing standard errors based on asymptotic theory obviously do not apply. We therefore implement three complementary approaches to inference. First, we use the nonparametric bootstrap, where we repeatedly resample

\footnotetext{
${ }^{3}$ Any other normalization procedure would yield identical results, up to a multiplicative constant.

${ }^{4}$ Merseyside encompasses both Everton F.C. and Liverpool F.C. fans. A backlash among Everton fans would dilute any treatment effects for the hate crime analysis, biasing against finding an effect.

${ }^{5}$ Appendix Figure A.1 shows that public interest in Salah-as measured by Google searches in the U.K. - spiked shortly after he was signed in the summer of 2017 and then began to steadily increase afterwards through mid-2018.

${ }^{6}$ Therefore, if there are $T$ posttreatment periods, we obtain $T$ treatment effect estimates. In addition, we compute the treatment effect averaged over the $T$ posttreatment periods as a simple summary of the treatment effect.
} 
control units and reestimate the model to generate a bootstrap distribution and standard error for the treatment effect estimator. Second, we conduct a permutation test where we reshuffle units' treatment status to generate a null distribution for the treatment effect estimator, analogous to the procedure in Abadie, Diamond, and Hainmueller (2010). Third, we conduct a placebo test using other types of crime, collected by the U.K. Home Office, that are unlikely to be affected by changes in anti-Muslim sentiment. If we find that the effect size for hate crimes is comparable to that for other types of crime, it would suggest that the results are capturing a more general decline in crime rather than an effect of Salah.

Appendix A provides greater detail on the data, research design, and methods for the hate crime analysis. It also presents the results of an alternative method of estimating the treatment effect-a generalized difference-in-differences regression with two-way fixed effects. This approach yields very similar results.

\section{Results}

The main results are presented in Figure 2. The top plot shows the actual outcome data for Merseyside, along with the imputed counterfactual for Merseyside. The bottom plot shows the difference between the observed and imputed outcomes in all periods for Merseyside and all other permutations of the treatment assignment. ${ }^{7}$ In both plots, the shaded region indicates the posttreatment period. In the posttreatment period, the difference between the observed and imputed outcomes is the treatment effect estimate.

If the matrix completion method is performing well, the imputed estimates should closely match the observed outcomes in the pretreatment period. Reassuringly, this is the pattern we see. In the top panel, the two lines in the pretreatment period track each other closely. In the bottom plot, the pretreatment line is close to 0 in most periods. While it fluctuates at times, there does not appear to be a trending pattern in the pretreatment period that would cause concern about the validity of the treatment effect estimates.

Moving on to the posttreatment periods, the observed levels of hate crime in Merseyside are consistently lower than the predicted level from the synthetic control unit. Averaging across all months in the posttreatment period, the difference between the observed outcome and the synthetic control is -0.275 annualized hate crimes per 1,000 residents. Compared with the counterfactual imputed average in the posttreatment period, this treatment effect represents a $16 \%$ drop in hate crimes. The bootstrap-based standard error for the treatment effect, averaging over posttreatment periods, is 0.069 and the central $95 \%$ confidence interval is $[-0.401,-0.154]$. Looking at the estimates month-by-month, the differences between the observed and imputed outcomes begin soon after Salah agreed to join Liverpool, in June

\footnotetext{
${ }^{7}$ That is, each gray line shows the matrix completion results if we pretend that one of the control units was, in fact, treated.
}

2017, and persist through at least April 2018-the last month in our dataset.

The bottom plot in Figure 2 shows the estimated treatment effect for Merseyside, in black, alongside the placebo treatment effect estimates for every other unit, in gray. ${ }^{8}$ This plot shows that the decrease in hate crimes in Merseyside is large relative to the placebo estimates. No placebo unit's treatment effect estimates are as consistently negative as Merseyside's. When we average across posttreatment periods, Merseyside has the largest decrease in hate crimes. Only one placebo unit has a treatment effect estimate that is larger in absolute value - and this is an increase in hate crimes relative to its respective synthetic controls. With these statistics, we can calculate one-sided and two-sided $p$-values. There are 24 possible permutations of the treatment assignment-Merseyside plus 23 placebo units - so the onesided $p$-value is $1 / 24=0.042$ and the two-sided $p$-value is $2 / 24=0.083$. This result suggests that the decrease in hate crimes observed in Merseyside is unusual relative to changes observed in other police jurisdictions.

The change in hate crimes is consistent with a Salah effect, but it is unclear whether Salah was the cause of the decline. Instead, it could also be that there was a general decline in crime in Merseyside that happened to coincide with Salah's arrival at Liverpool F.C. If this were the case, we might observe a decrease in hate crimes relative to other police jurisdictions, even if Salah's arrival at Liverpool F.C. had no direct effect on hate crimes.

The placebo outcome analysis helps to address this concern. If there were a general decline in crime, the estimated treatment effect on hate crimes would not be distinctive relative to the treatment effect on other types of crime. Figure 3 shows the treatment effect estimates for each of 15 different types of crimes-hate crimes, plus the 14 types tracked in the U.K. Home Office police data. The results show that the decrease in hate crimes is larger than changes observed for other types of crime in Merseyside. Recall that the treatment effect for hate crimes was a $16 \%$ decrease relative to the synthetic control in the posttreatment period. No other crime category saw such a large relative decrease, and only one, "drugs," had a change that was larger in magnitude - and it was an increase in crime by $19.5 \%$. Thus, the drop in hate crimes after Salah was signed does not appear to be attributable to a general decrease in crimes in Merseyside.

Overall, we interpret these results to support the hypothesis that Salah's arrival at Liverpool F.C. caused a decrease in extreme acts of bigotry. Hate crimes in Merseyside were lower after Salah was signed than we would expect given prior hate crime trends and the trends of other police jurisdictions after Salah was signed. This decline was more extreme than we would expect based on chance alone, and the decrease in hate crimes was more pronounced than the decrease in any other crime category. Taken together, the evidence

\footnotetext{
${ }^{8}$ In implementing this method, we omit the West Yorkshire police force because we only have data for two pretreatment months. In all, there are 23 placebo units we use for the permutation procedure.
} 


\section{FIGURE 2. Synthetic Control Results for Hate Crimes Analysis}

(a) Observed and imputed outcomes for Merseyside

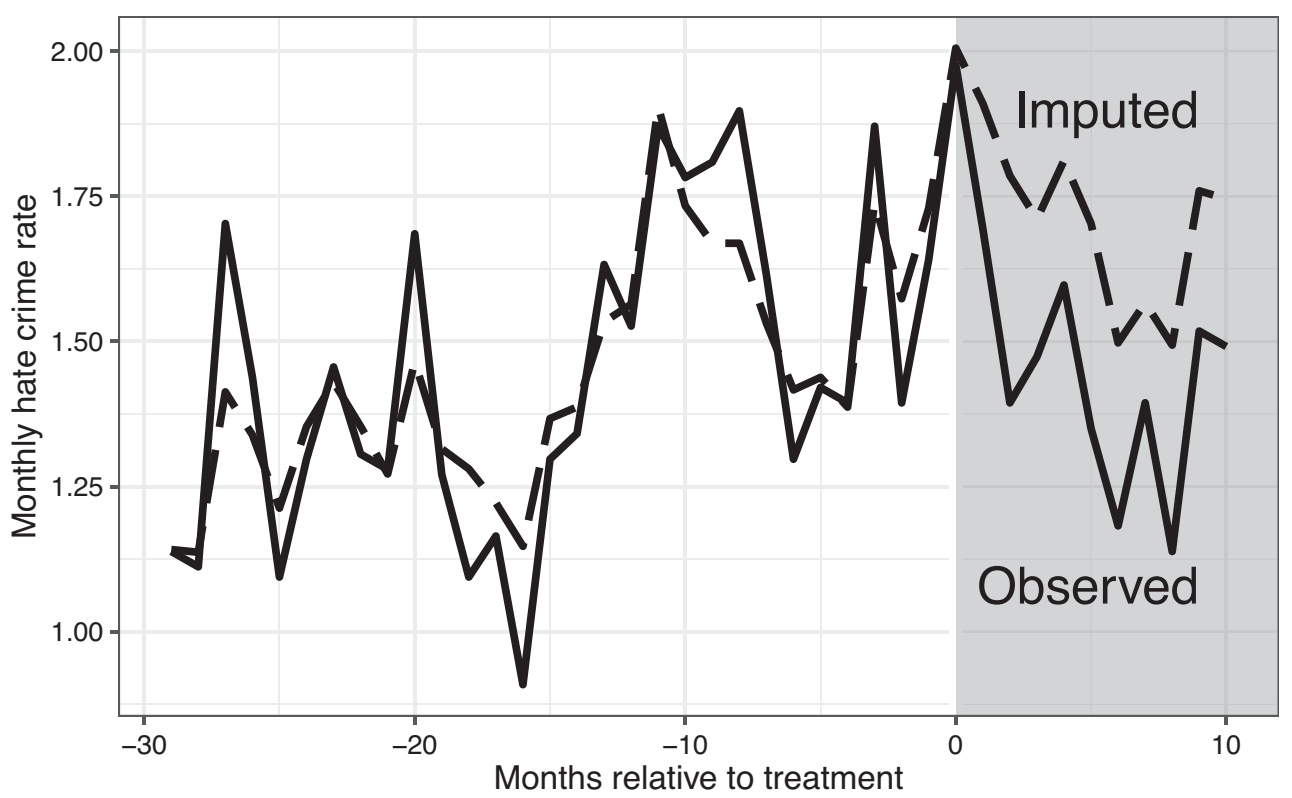

(b) Treatment effect estimates for Merseyside and placebo units

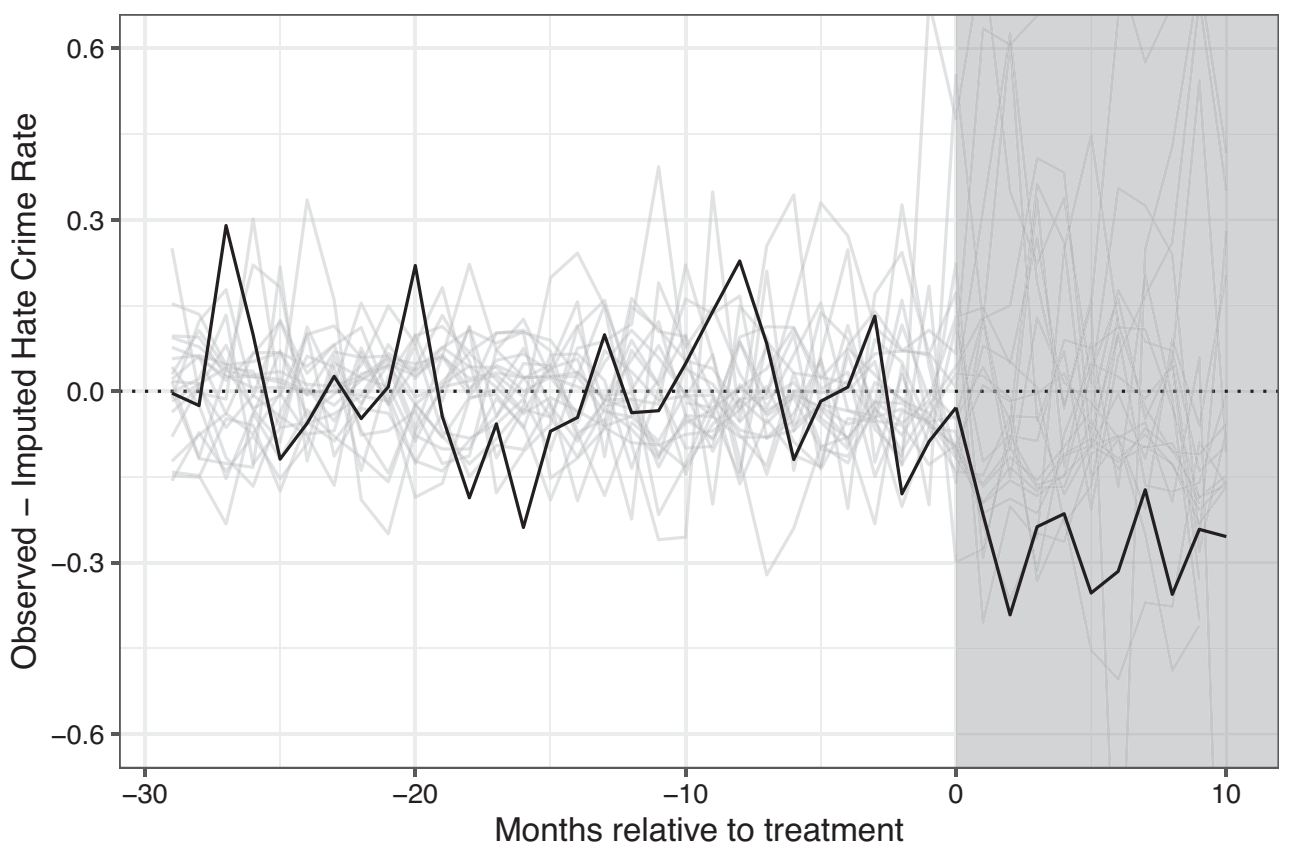

Note: The top panel shows the observed (solid line) and imputed (dashed line) monthly hate crime rates in Merseyside. The bottom panel shows the difference between the observed and imputed outcomes. In the posttreatment period, this is the estimate of the treatment effect. The black line shows the estimates obtained for Merseyside, and the gray lines show the estimates obtained when we treat each of the control units as if it were treated. The fact that the Merseyside estimates are consistently lower than the control group estimates provides evidence that our treatment effect estimates are unlikely to be due to chance.

points to Salah's rise in prominence causing a decrease in hate crimes in Liverpool F.C.'s home county. ${ }^{9}$

\footnotetext{
${ }^{9}$ Some may object to the hate crimes analysis because only about $39 \%$ of hate crimes targeted Muslims (see Appendix A). Considering
}

that Muslims make up only $5 \%$ of the British population, they are significantly overrepresented among hate crime victims. Another objection is that Islamophobia may be underlying some other crime categories that are used in the placebo tests. While this is a possibility, it would bias against our findings, since the trends for all crimes would look more similar to the trend for hate crimes. 


\section{FIGURE 3. Synthetic Control Results for All Crime Types in Merseyside}

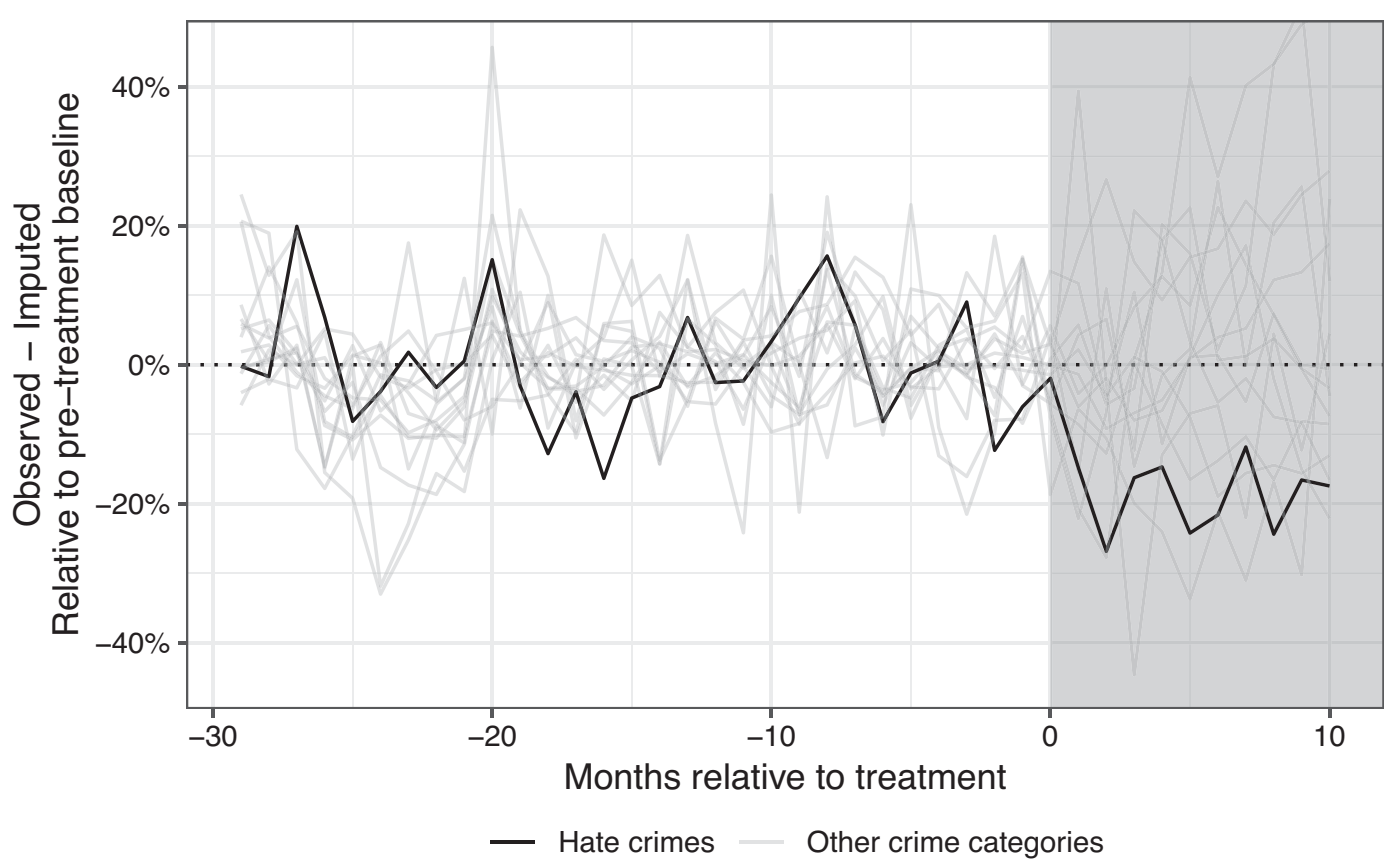

Note: The black line shows the treatment effect estimate for hate crimes and the gray lines show treatment effect estimates for each of 14 types of crimes defined by the U.K. Home Office. To generate estimates on comparable scales across crime types, the treatment effect estimates are expressed as a percentage of the pretreatment mean for each crime type. The estimated treatment effect on hate crimes is consistently more negative than the estimate for any other crime outcome.

\section{ANALYSIS OF U.K. SOCCER FANS' TWEETS}

Our analysis of hate crimes in the U.K. provides evidence that Salah joining Liverpool F.C. may have decreased hate crimes in Merseyside relative to their expected rates if he had not joined Liverpool F.C. Although hate crimes are extremely harmful and consequential, they are quite rare and extreme events. As such, they tell us little about how Salah's signing may have influenced more quotidian forms of anti-Muslim behavior among Liverpool F.C. fans. To gain more insight into this question, we analyze approximately 15 million tweets produced by U.K.-based soccer fans in the period preceding and following Salah joining Liverpool F.C. We find a meaningful decline in the rate of anti-Muslim tweets among Liverpool F.C. fans.

\section{Data and Research Design}

Looking at soccer fans based in the U.K., we compare the frequency of anti-Muslim tweets produced by fans of Liverpool F.C. with tweets produced by fans of other English clubs over time. We began by using Twitter's REST API to scrape the account IDs of all followers of the top five most followed teams in the English Premier League: Manchester United F.C. (19 million followers), Arsenal F.C. (14 million), Chelsea F.C. (12 million), Liverpool F.C. (11 million), and Manchester City F.C. (6 million). We also scraped the followers of Liverpool F.C.'s cross-town rival Everton
F.C., a smaller team with 1.75 million followers that is also located in the city of Liverpool. Fans of both clubs are nearly identical in terms of demographics: the home stadiums are within walking distance of each other, there are no historic political, religious, or social differences between their fanbases, and many Liverpudlian families are mixed in their allegiances (Borden 2014). Evertonians thus constitute the closest comparison group in the sample, with one key difference as a result of their fierce rivalry: exposure to Salah may skew negative for Evertonians, but is positive and goal-aligned for Liverpool F.C. fans.

After obtaining followers' account IDs, we collected our sample of tweets as follows. First, to ensure that the users in our sample had been soccer fans prior to Salah joining Liverpool, we subset our follower IDs to the oldest 500,000 followers of each club and subset to those who live in the U.K. based on the text of their selfreported locations. Once we identified longtime Twitter followers of English Premier League teams that were likely to be located in the U.K., we randomly sampled 10,000 followers from each team. We used Twitter's REST API to scrape up to 3,200 of the most recent tweets published by each of these 60,000 U.K. soccer fans. ${ }^{10}$ This resulted in a dataset of approximately

\footnotetext{
${ }^{10}$ The 3,200 tweet limit is imposed by Twitter's API. For most Twitter users, we observe their entire Twitter timelines beginning on the day they first joined the platform. For $84 \%$ of users in our sample we have tweets from before and after Salah joined Liverpool.
} 
15 million tweets produced by the 60,000 English followers of the "Big Five" clubs of English soccer, as well as Everton F.C.

To identify anti-Muslim tweets in our dataset, we began by identifying all tweets about Muslims using a generic keyword search, and using word2vec (a neural network that processes text) to find other relevant terms in the data. We included relevant keywords that featured in the top 50 words that the word2vec model indicated were most similar to the terms "Muslim" and "Islam." About 44,000 of the 15 million tweets in our dataset contained one of these relevant keywords. We then took a sample of about 1,500 of these tweets and trained three native English speakers to code each of these tweets as antiMuslim or not.

Using this human-coded data, we trained a Naive Bayes classifier to classify all of our tweets containing one of the keywords described above as anti-Muslim or not. ${ }^{11} \mathrm{We}$ then used this classifier to classify all 44,000 tweets relevant to Islam or Muslims in our dataset as anti-Muslim or not. ${ }^{12}$ These classified tweets allowed us to compute the monthly proportion of relevant tweets (discussing Islam or Muslims) that were anti-Muslim. ${ }^{13}$ More details about the data collection and coding, as well as descriptive statistics, are presented in Appendix B.

Our main analysis of the Twitter data uses the same matrix completion method used in the hate crime analysis. This method allows us to use the rates of anti-Muslim tweets posted by fans of Liverpool F.C. and other clubs in the pretreatment period to construct a synthetic control unit for Liverpool F.C. fans in the posttreatment period. This, in turn, enables us to estimate how the rates of anti-Muslim tweets among Liverpool F.C. fans' tweets changed after Salah joined the club, relative to what they would have been if he had not joined. The previous section provides more details on this method.

\footnotetext{
${ }^{11}$ Our classifier's out of sample performance yielded scores of $88 \%$ Accuracy, 98\% Precision, 90\% Recall, and an F1 score (harmonic mean of Precision and Accuracy) of $94 \%$. However, because antiMuslim tweets were relatively rare in our data, and our training dataset was not balanced, Balanced Accuracy (i.e., the average of the proportion of tweets classified correctly in each class individually) is a better and more conservative measure of classifier performance. Our classifier performed with $70 \%$ Balanced Accuracy. Given that intercoder agreement among human coders was $76 \%$, we are satisfied that our classifier gives us a reasonable, if imperfect, measure of anti-Muslim sentiment in our tweets.

${ }^{12}$ Tweets that did not contain relevant keywords were classified as irrelevant.

${ }^{13}$ This measure is less sensitive to changes in the salience of topics related to Muslims or Islam than a related outcome: the proportion of anti-Muslim tweets in fans' total tweets. For example, terror attacks are often followed by an uptick in anti-Muslim language, but this is generally accompanied by much larger increases in tweets defending Muslims and Islam or condemning Islamophobia, as well as upticks in neutral tweets discussing the event (Magdy, Darwish, and Abokhodair 2015). We thus focus only on tweets relevant to Muslims or Islam to alleviate this concern.
}

\section{Results}

The results are presented in Figure 4. The top plot shows the actual outcome data for Liverpool F.C. fans, along with the imputed counterfactual for these fans. The bottom plot shows the difference between the observed and imputed outcomes in all periods for Liverpool F.C. fans as well as for fans of four other large football clubs (Arsenal, Chelsea, Manchester United, and Manchester City) and fans of Everton. In both plots, the shaded region indicates the posttreatment period. In the posttreatment period, the difference between the observed and imputed outcomes is our estimate of the average treatment effect on the treated unit (ATT).

As in the hate crime results, if the matrix completion method is performing well, the imputed estimates should closely match the observed outcomes in the pretreatment period. Again, we observe this pattern: the pretreatment imputed and observed outcomes for Liverpool tend to be very similar, and there does not appear to be a pretreatment trend that would threaten the validity of the treatment effect estimates.

Examining the posttreatment periods, the observed monthly proportions of anti-Muslim tweets among Liverpool F.C. fans are consistently lower than what we would predict based on the synthetic control. Averaging across all months in the posttreatment period, the difference between the observed outcome and imputed outcome of the proportion of anti-Muslim tweets is -0.035 (bootstrap-based SE $=0.006$ ). Compared with the pretreatment average among Liverpool F.C. fans, this treatment effect represents a $47.8 \%$ drop in the proportion of anti-Muslim tweets (from 0.073 to 0.038). Looking at the estimates month by month, the differences between the observed and imputed outcomes begin soon after Salah agreed to join Liverpool F.C., in June 2017, and persist through at least May 2018 - almost a year after Salah joined the team.

We employ the same permutation inference approach as in the hate crime analysis. Only for Liverpool F.C. followers do we estimate a consistently negative treatment effect in the posttreatment period. The placebo estimates tend to oscillate between positive and negative treatment effects, while the Liverpool treatment effect estimates are negative in every posttreatment month but one-again suggesting that the observed estimate for Liverpool F.C. followers is unlikely to have occurred by chance. As a robustness check, we again present a generalized difference-in-differences approach in Appendix B. That analysis method generates very similar estimates as the ones reported here.

\section{ROBUSTNESS AND GENERALIZABILITY TESTS}

The hate crime and hate speech analyses show that exposure to Mohamed Salah reduced prejudice in Liverpool, providing support for the parasocial contact hypothesis using real-world behaviors. Hate crimes in Merseyside were lower and anti-Muslim tweets among 


\section{FIGURE 4. Synthetic Control Results for Twitter Data}

(a) Observed and imputed outcomes for Liverpool

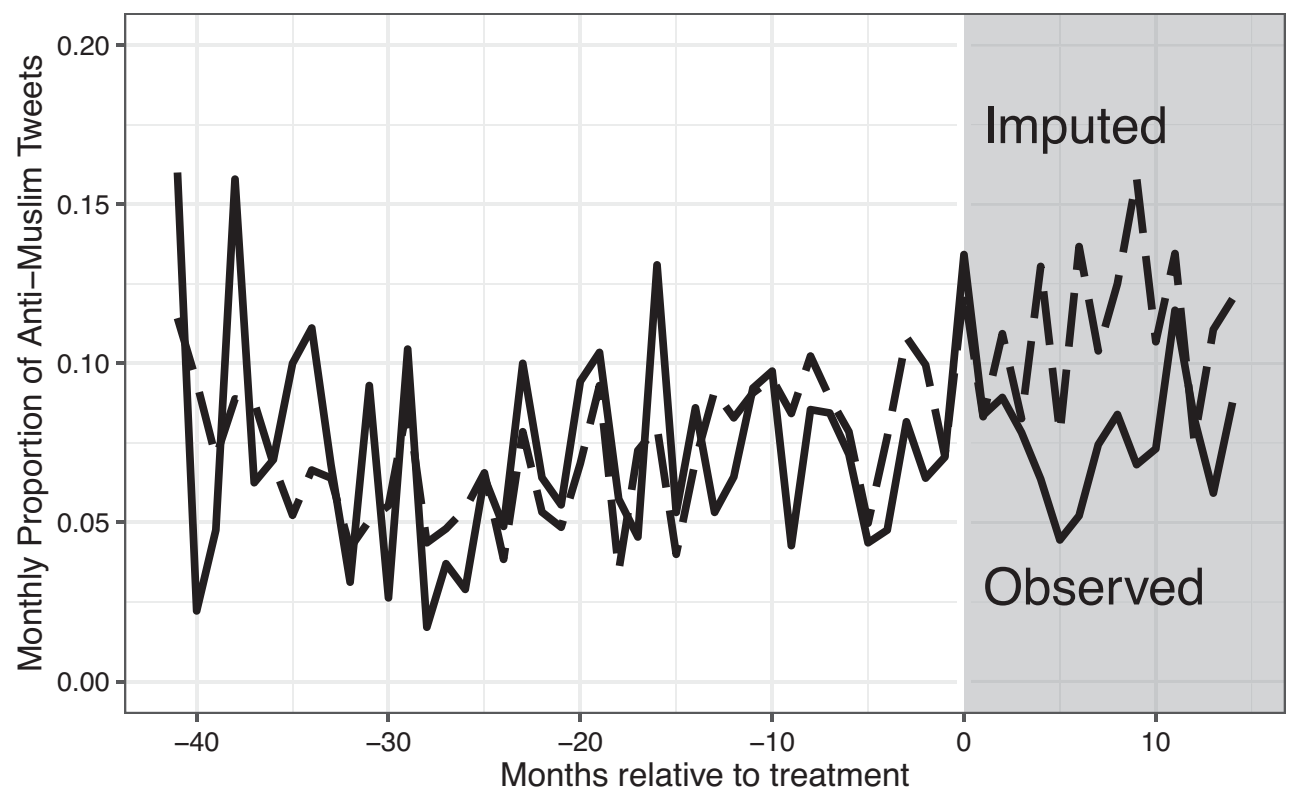

(b) Estimated ATT in every period (Liverpool F.C. vs. Other Clubs)

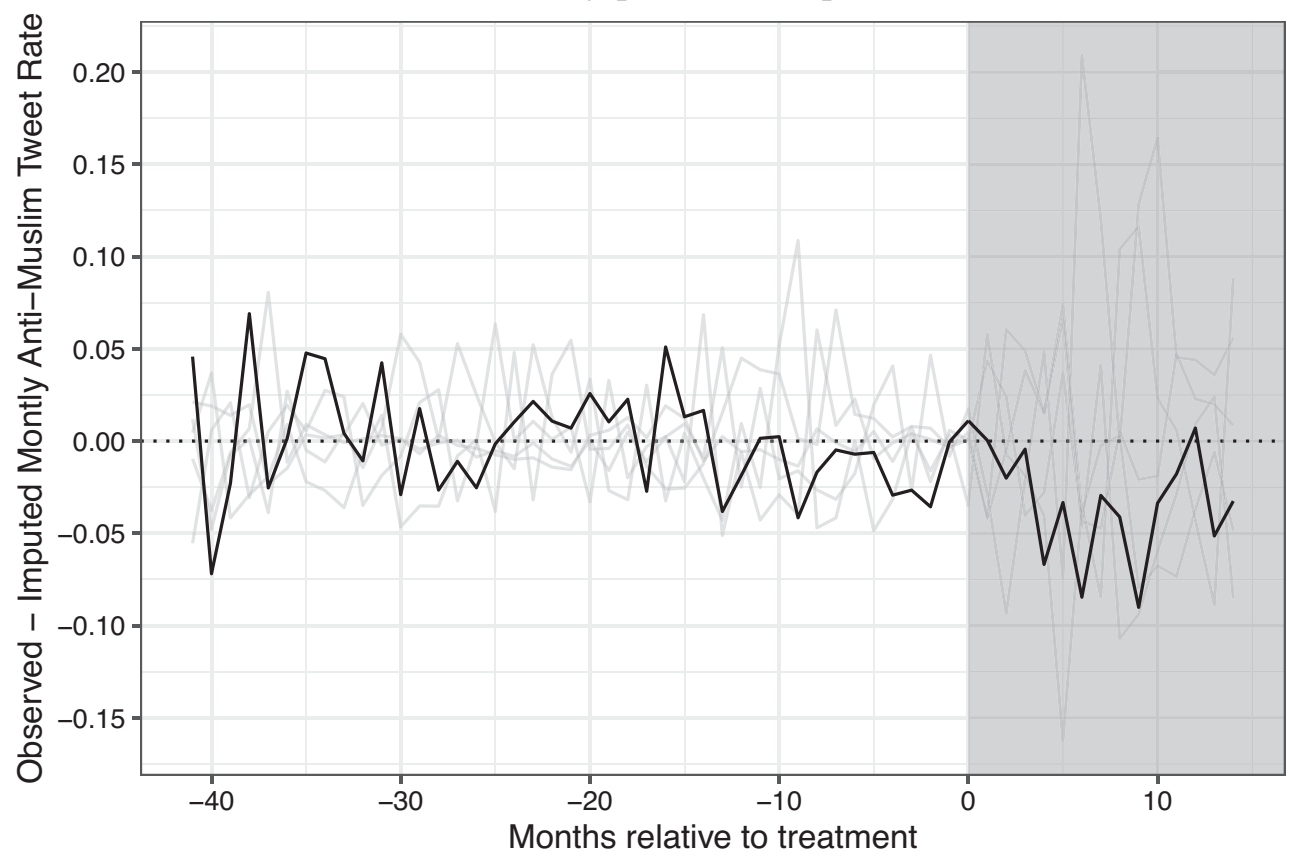

Note: The top panel shows the observed (solid line) and imputed (dashed line) monthly proportion of anti-Muslim tweets in Liverpool F.C. fans' tweets that are relevant to Muslims or Islam. The bottom panel shows the difference between the observed and imputed outcomes. In the posttreatment period, this is the estimate of the ATT for Liverpool compared with that of other prominent English clubs.

Liverpool F.C. fans were less common after Salah was signed relative to what we would have expected based on prior trends among these treated groups and based on trends among control groups, whose exposure to Salah was lower in both quantity and quality. In this section, we briefly summarize several extensions and robustness checks to these event study analyses.
First, one potential threat to inference is that there there were two Islamist terrorist attacks - the Manchester Arena and London Bridge attacks - roughly one month before Salah was signed by Liverpool F.C. If these attacks led to spikes in Islamophobia in the targeted cities, our results could be driven by the trajectory of the control units rather than a change in 
behavior in Liverpool. To verify that our hate crime results are not driven by a spike in hate crimes in these cities, we rerun the analysis but exclude London and Manchester. The hate crime results are virtually unchanged, as shown in Figure A.4.

Robustness checks for the Twitter analysis are more difficult, as these two cities contain four of the five clubs that make up the control group in the Twitter analysis. ${ }^{14}$ However, there is reason to think that the Twitter results are not driven by upticks in Islamophobia in these cities: the treatment effects we uncover last well beyond the terrorist attacks. The attacks would have had to have caused a long-term, sustained increase in anti-Muslim tweets among just followers of London- and Manchester-based clubs to generate the patterns that we observe. This would run counter to patterns observed in studies of the effect of terror attacks on anti-Muslim tweets, which tend to spike and then re-equilibrate quickly following attacks (Magdy, Darwish, and Abokhodair 2015).

A second possibility is that the Twitter results are driven by an uptick in anti-Muslim sentiment among fans of rival clubs - representing a backlash to Salah. To rule out this possibility, we conduct an additional analysis comparing tweets of rival fans to tweets from people who do not follow any soccer clubs. As we detail in Appendix B.5, rival fans did not increase antiMuslim tweets relative to non-soccer fans, after Salah's signing. In short, we find no evidence of a backlash effect.

Third, if parasocial contact is indeed reducing prejudice toward Muslims, we may wonder whether other Muslim players have induced a similar effect. In probing the generalizability of our results, we turn our attention to another Liverpool F.C. player, Sadio Mané-a Senegalese Muslim who joined the squad exactly one year before Salah and who also demonstrates his religiosity to fans on occasion. Did Mané have a similar effect on prejudice as Salah? Ex ante, Mané seems to fit the criteria for the parasocial contact hypothesis somewhat less neatly than Salah-particularly sustained exposure and salient group identity. Mané is not as heavily covered by the international or local media when compared with his Egyptian teammate. We scraped the headlines of Liverpool's most widely circulated newspaper, The Liverpool Echo, to analyze trends in coverage of the two players. We find that Manés signing captured around 3\% of headlines relative to Salah's 9\% (Figure A.7), suggesting that exposure to Mané is weaker compared with exposure to Salah. Moreover, Mané's group identity is likely less salient. His name is not as recognizably as Muslim as "Mohamed," and Black Muslims tend to be perceived as less representative of Islam (Harvard 2017). Fans have yet to create chants about Mané's religious identity (as they have done with Salah), speaking to the difference in group identity salience between the two players. These factors suggest a weaker perceived link

\footnotetext{
${ }^{14}$ Chelsea and Arsenal are both located in London, and Manchester United and Manchester City are of course located in Manchester.
}

between player and Muslim identity, undermining the salience of group identity needed for parasocial contact to take effect.

Nonetheless, we look for evidence of a "Mané effect" using the same research designs. We find no such effect on hate crimes when constraining the study period to the pre-Salah era and taking the date of Mané's signing as the relevant time break (Figure A.8). We do, however, find a Mané effect on anti-Muslim tweets similar in magnitude to the Salah effect (Figure A.9). Recall that the Twitter analysis focuses only on soccer fans, who are more likely to be familiar with a less publicized player like Mané, shedding some light on why we might detect an effect solely for the Twitter analysis. One response to an open-ended question on our survey of Liverpool F.C. fans, detailed in the next section, underscores the idea that club fans recognize Mané as Muslim: "I think with having Mo Salah and Mané, people should read more into Muslim life and try to understand the kind of people our favourite players are."

In sum, we find support for the parasocial contact hypothesis in two event studies centered on Salah's rise to fame. These results are driven neither by backlash to contemporaneous events nor by backlash to Salah among fans of rival clubs. We also test parasocial contact by replicating our analysis for another Muslim player. We find some evidence of generalizability by studying Salah's teammate Sadio Mané. As expected for a player with weaker media coverage and a less salient Muslim identity, we find evidence of prejudice reduction among Liverpool F.C. fans who closely follow their club players, but not among broader residents of Merseyside. These additional analyses help rule out alternative explanations for the Salah effect, while increasing confidence in the parasocial contact hypothesis by testing its applicability to another Muslim player.

\section{ANALYSIS OF SURVEY EXPERIMENTAL EVIDENCE}

The evidence presented thus far suggests that exposure to Salah may have reduced anti-Muslim behavior among Liverpool F.C. fans. As we outlined earlier, the parasocial contact hypothesis suggests that sustained, positive exposure to a minority group member can reduce prejudice when that individual's group membership is salient. The group salience assumption is critical for all theories of intergroup contact-any positive effects should extend beyond the specific contact partner and generalize to other members of the out-group (Al Ramiah and Hewstone 2013; Brown and Hewstone 2005). This "generalization" of positive effects requires that the contact partner is viewed as representative of their group, without confirming negative stereotypes (Bond 2020; Ensari and Miller 2002). While we have argued that Salah's first name, family, and public displays of religiosity all highlight his identity as a Muslim, our analysis of aggregate-level observational data does not enable us to directly test whether 
awareness of Salah's Muslim identity leads individuals to express less prejudice toward Muslims as a whole.

To test the generalization assumption directly, we design a survey experiment to evaluate whether priming Liverpool F.C. fans to think about Salah's Muslim identity causes them to express more positive attitudes towards Muslims writ large. ${ }^{15}$ Our survey experiment does not directly test whether parsocial contact reduces prejudice, as all respondents have received positive and sustained exposure to Salah. Instead, this experiment enables us to evaluate, conditional on exposure, whether highlighting Salah's group identity reduces generalized prejudice toward Muslims-testing a necessary condition of parasocial contact.

\section{Experimental Design}

To evaluate this key condition of the parasocial contact hypothesis - the generalization assumption-we conducted a survey targeting people who "like" the Liverpool F.C. page on Facebook and who live in the U.K. ${ }^{16}$ These users saw a Facebook advertisement stating: "Help us research L.F.C.! Love Liverpool F.C.? Take 2 mins. to help us research Liverpool fans!" The survey was launched from October 2018 to January 2019, until $\$ 1,500$ worth of clicks were exhausted. ${ }^{17}$ Before taking the survey, respondents were shown a page that explained their rights as research subjects, gave contact information for the investigators and the IRB, and required participants to affirm that they were at least 18 years old.

We presented people in the treated group with a picture of Salah prostrating in prayer and the following text, which highlights Salah's Muslim identity without affirming negative stereotypes about Muslims:

In addition to his goal scoring, Salah is known for an attachment to his Muslim identity both on and off the pitch. After every goal he scores, Salah touches his head to the ground in prayer. He also fasts during Ramadan (except on match days) and shares well wishes with his followers on social media during Islamic holidays. He named his daughter Makka after Islam's holiest site (Mecca). ${ }^{18}$

\footnotetext{
${ }^{15}$ As described in Appendix D, we also attempted to test the positivity condition by providing prompts highlighting Salah's success or casting doubt on his ability to maintain his successful streak. However, our manipulation did not appear to affect respondents' perceptions of Salah's performance, as shown in the manipulation check in Figure A.11. This manipulation failure is perhaps because fans already have strong views on players' performance and because Salah was playing well during the study period, rendering our experimental treatment not credible. For these reasons, we relegate discussion of this arm of the survey experiment to Appendix D.

${ }^{16}$ The majority of the respondents were indeed Liverpool F.C. fans. Around $85 \%$ mentioned that they follow Liverpool F.C. "Very closely," and over 98\% mentioned they follow Liverpool F.C. at least "Somewhat closely."

${ }^{17}$ The survey experiment was approved by the Stanford University Institutional Review Board, protocol \#47168 and preregistered with EGAP, protocol \#20181115AB.

${ }^{18}$ As this was a factorial design, people in the treated group were also presented with text portraying Salah as succeeding or failing. See
}

The control group was assigned to a pure control and thus did not receive any treatment. All respondents who were not in the control condition saw the following statement, which preceded each of the vignettes: "As you probably know, Mohamed Salah is an Egyptian winger who joined Liverpool F.C. in June 2017." A table showing balance on pretreatment covariates is presented in Appendix D.3.

The outcomes variables comprise three survey items that capture whether (1) the respondent believes there is a "fundamental clash between Islam and British values," (2) the respondent has "some" or "a lot" in common with Muslims in the U.K., and (3) the respondent thinks immigrants "generally have a positive influence on the U.K." All of these outcomes are coded as binary in a pro-tolerant direction. We then used the first principal component generated by these items as a fourth, composite outcome. ${ }^{19}$ These outcomes capture three communities linked with Salah to varying degrees: Islam in general, Muslims in the U.K., and immigrants. Salah's public piety explicitly links him to Islam but less so to Muslims and immigrants in the U.K. - only $5.8 \%$ of U.K. residents born abroad are from the Middle East or North Africa (Office for National Statistics 2019), tempering expectations around these outcomes.

We estimate the main effect of the religiosity treatment, which is defined as the effect of the religiosity treatment, averaged over the levels of other factors. This definition is directly analogous to the average marginal component effect estimand commonly used in conjoint experiments (Hainmueller, Hopkins, and Yamamoto 2014). Due to randomization of the treatments, the main effects can be estimated without bias via linear regression. ${ }^{20}$

\section{Results}

Figure 5 shows a coefficient plot from regressions estimating the average treatment effect of the religiosity treatment on the four outcome measures, which are detailed on the $y$-axis. We find some effects of the Religiosity vignette on tolerance. In particular, reading a vignette emphasizing Salah's Muslim identity sparked a small but statistically significant increase in respondents' belief that Islam is compatible with British values. Reminding respondents of Salah's Muslim identity and

\footnotetext{
Appendix D.2 for more details. In the analysis below, we pool across both the success and failure treatments.

${ }^{19}$ The outcomes were scaled to have mean 0 and unit variance for the principal component analysis. The first principal component explained $76 \%$ of the total variance.

${ }^{20}$ Due to a coding error in the survey experiment, the control group was initially much larger than the treatment group. We corrected this survey coding error midway through data collection. However, this correction introduced the complication that not all units had equal treatment probabilities. To obtain unbiased treatment effect estimates, we weight all observations by the inverse probability of the realized treatment assignment. All the results presented here represent the weighted results.
} 


\section{FIGURE 5. Coefficient Plots Representing the Main Effect of the Religiosity Treatment on the Four Outcomes Relative to the Pure Control Condition}

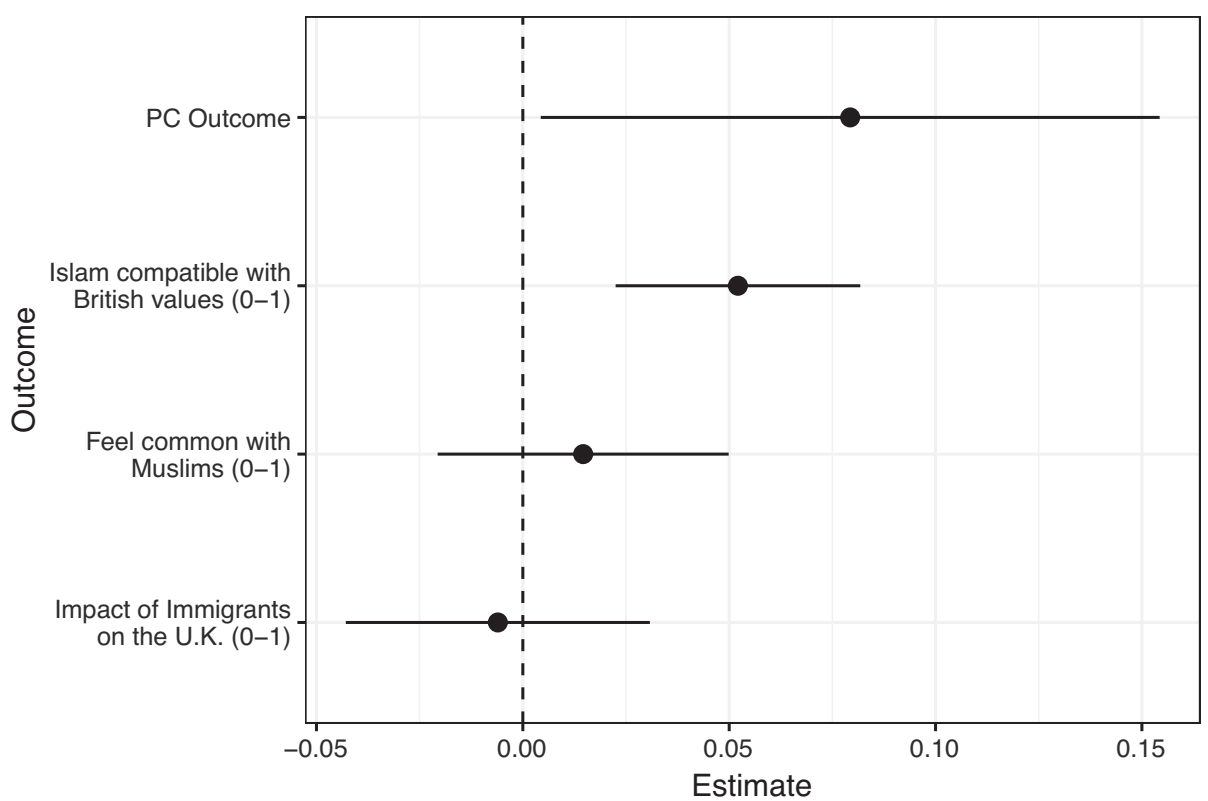

Note: The top outcome represents the first principal component of the other three outcomes and has a mean of zero and unit variance. The other three outcomes are binary. The bars show $95 \%$ robust confidence intervals.

practices made them around 5 percentage points more likely to say that Islam is compatible with British values relative to the control group baseline of $18 \%$. The treatment effect on the Religiosity vignette also increased the principal component outcome by $8 \%$ of one standard deviation. The Religiosity prime also moved the outcome capturing tolerance toward British Muslims in the expected direction, although this difference is not statistically significant, whereas tolerance toward immigrants remained unchanged. These effects are stable across various social and political subgroups. ${ }^{21}$

This experiment provides further evidence in support of the parasocial contact hypothesis generally and the importance of group salience in particular. When reminded of Salah's Muslim identity, respondents express more tolerant attitudes towards Islam-consistent with the idea that group identity must be salient in order for positive feelings towards an individual to extend to the out-group as a whole.

\section{DISCUSSION}

Our findings provide diverse sources of evidence for the parasocial contact hypothesis. Our analyses demonstrate that positive and sustained exposure to

\footnotetext{
${ }^{21}$ Full regression results are presented in Table A.5. As we show in Appendix D.4, these effects do not differ for those who are more or less inclined to like Salah, be empathetic, or reside in Liverpool, suggesting a consistent effect of group salience across social subgroups.
}

Mohamed Salah likely reduced hate crimes and antiMuslim speech on Twitter among Liverpool F.C. fans. We find that hate crimes and anti-Muslim tweets decreased among people with frequent, positive exposure to Salah relative to counterfactual groups with less frequent and less positive exposure. These two outcomes are both costly and public, typically committed by those with high levels of prejudice. Observing such a tangible effect in this context is thus particularly compelling evidence of the effects of parasocial contact, especially given that Liverpool F.C. fans reside in a city that is less ethnically diverse than the rest of England and Wales and that has a relatively high prevalence of hate crimes (Liverpool City Council 2011). These results provide real-world evidence that exposure to celebrities from stigmatized groups can reduce prejudice.

Our analyses of observational data provide support for the parasocial contact hypothesis. These analyses do not, however, allow us to directly test the assumptions needed for parasocial contact to increase tolerance. Therefore, we use an original survey experiment of Liverpool F.C. fans to test one of the primary assumptions underpinning all theories of intergroup contact: that positive effects will generalize beyond the contact partner to the entire out-group when the contact partner's out-group identity is salient. Our experiment allows us to examine whether highlighting Salah's Muslim identity encourages fans to make an inferential leap from Salah to Muslims as a whole and thus express lower levels of Islamophobia in general. The experiment demonstrates that being reminded of Salah's strong Muslim identity causes Liverpool 
F.C. fans to express lower levels of Islamophobia, providing direct evidence of the mechanics underlying the parasocial contact hypothesis.

The parasocial contact hypothesis, however, also points to the importance of positive and sustained exposure. This raises the question of which of these aspects is most important in driving the results in our analyses of hate crimes and tweets posted by soccer fans. In these analyses, the control groups are still exposed to Salah-although presumably the exposure is less sustained and perhaps less positive than it is for Liverpool F.C. fans. Because we cannot measure these aspects of parasocial contact directly, we cannot parse out the relative importance of positivity and sustained exposure in the observational results. Future research on parasocial contact should examine the conditions thought to be important for mediated contact to translate to real-world prejudice reduction.

How generalizable are these results? Our findings suggest that positive and sustained exposure to celebrities should reduce prejudice when the celebrity's group identity is salient. Indeed, our additional analyses of Salah's teammate Sadio Mané show the potential for generalizability. However, to further understand the generalizability of the phenomenon we document, future work should specify three (related) components of the compound treatment we study here: the positive media coverage Salah receives, his success on the pitch, and the fact that he does not take public political stances.

First, following the parasocial contact literature, we expect that the Salah effect is conditional on positive media coverage. Media commentary about Salah has been almost uniformly positive since his arrival at the club, but it remains unclear how parasocial contact operates when the media stigmatizes a celebrity. Media portrayals - whether they appear in news stories (e.g., Gilliam and Iyengar 2000) or entertainment media (e.g., Mastro and Tropp 2004) - form the primary basis of attitudes toward out-groups for many individuals. Mass media has often portrayed marginalized groups in negative or otherwise stereotypical ways, further contributing to marginalization (Ramasubramanian and Murphy 2014). Laboratory experiments have shown that positive media portrayals of celebrities can help to reduce stated prejudice. In experiments using news stories about celebrities such as Kanye West and Beyoncé Knowles, Ramasubramanian (2015) shows that stereotypical and counter-stereotypical portrayals can shape perceptions of African Americans.

Second, another component of the positive exposure to Salah is his success with Liverpool F.C. Anecdotal evidence points to a backlash effect on prejudice when celebrity athletes underperform. Salah has enjoyed phenomenal success at the individual and team level during the study period - so much so that our manipulation check on a treatment arm priming fans to think of him as a failure was unsuccessful. Nonetheless, the positive effects of parasocial contact may well be conditional on performance, a claim made by several elite soccer stars of immigrant descent. When he left the German national team because of alleged racist abuse,
Mesut Özil, who is of Turkish descent, stated: "I am a German when we win and an immigrant when we lose" (Stanley-Becker 2018). Similarly, Romelu Lukaku has written that when he plays well, newspapers refer to him as the "Belgian striker," but when he plays poorly, they refer to him as "the Belgian striker of Congolese descent" (Lukaku 2018).

This aspect of elite sports and other high-stakes, realworld domains makes them qualitatively different from television shows, the most commonly studied media in the parasocial contact literature (e.g., Bond 2020; Schiappa, Gregg, and Hewes 2005; 2006). Future work should study the extent to which parasocial contact relies on consistent, successful performances to reduce prejudice.

Third, taking political stances-especially on social justice issues - could shape the effects of celebrities on prejudice. At the time of writing, Salah has been notably silent on politics while some of his peers have spoken out against the discriminatory treatment of Muslims, often at great personal cost (Smith and Panja 2020). Observers note that Salah's avoidance of politics may have contributed to his broad-based appeal and therefore to his effect on Islamophobia (Al-Sayyad 2018). The net effect of celebrities speaking out on social or political issues, however, remains unclear. On the one hand, celebrities adopting a social or political cause may provoke backlash among some fans, thereby negating the "positivity" condition needed for parasocial contact to reduce prejudice. On the other hand, well-liked celebrities can also communicate experiences of marginalization in a way that encourages their fans to consider the perspective of marginalized group members, thus reducing prejudice through perspective-taking (Adida, Lo, and Platas 2018; Broockman and Kalla 2016; Simonivitz, Kezdi, and Kardos 2018). Even if speaking out on social issues will alienate a segment of the fanbase, celebrities may nonetheless choose to prioritize activism over broad fan support. The effectiveness of celebrity activism in confronting systematic racism, and whether there is indeed a trade-off between optimizing for broad-based appeal versus social change, are promising topics for future research.

These suspected trade-offs are illustrated by the case of American football player Colin Kaepernick, a Black quarterback who started in two conference championship games and one Superbowl. In 2016, Kaepernick began protesting against racism in policing by kneeling during the national anthem. The peaceful protest drew scorn from fans, media commentators, and conservative politicians. At the time of writing, Kaepernick has remained unsigned since the end of the 2016-17 season - a move that has been widely interpreted as collusion by team owners who fear backlash from mostly white fans (Reid 2017). Yet, his public stance and those of other prominent Black celebrities have raised awareness about racial disparities in policing. These demonstrations have contributed to a social movement that culminated in the largest protests in U.S. history in the summer of 2020 (Buchanan, Bui, and Patel 2020; Streeter 2020). Kaepernick's protest 
also inspired similar protests abroad, including Premier League players taking a knee before every game following the death of George Floyd at the hands of police in May 2020. Given the long history of celebrities and athletes using their platforms to address social and political challenges, a critical question for future research is when and how these actions shape attitudes, behaviors, and social norms.

Finally, future work should specify the social, emotional, and cognitive mechanisms underpinning parasocial contact. In addition to out-group identity salience, other possible mechanisms at play include undermining negative stereotypes (Fujioka 1999; Ramasubramanian 2013) and demonstrating vicarious contact with ingroup members (Ortiz and Harwood 2007; Vezzali et al. 2014; Wright et al. 1997). For example, Salah is known to be on friendly terms with white, British-born teammates from Liverpool-adjacent areas, which may reduce intergroup anxiety by proxy. Research disentangling these mechanisms holds important implications for generating scope conditions for Salah effects elsewhere.

\section{CONCLUSION}

Exposure to celebrities has become a quotidian feature of modern life both online and through traditional media channels. Yet we know relatively little about how these public figures may influence intergroup relations. In practice, traditional intergroup contact-positive, faceto-face interactions with friendship potential-is difficult to orchestrate and rare in the U.K. and beyond. Because most people rarely have meaningful interactions with members of out-groups, positive exposure to public figures has the potential to be particularly influential. We take a first step in quantifying the effect of such exposure by assessing the effect of exposure to a successful Muslim celebrity on Islamophobia. We find evidence that mediated exposure to public figures from stigmatized groups can mitigate prejudicial behaviors such as hate crimes and bigoted speech. We also provide evidence for a key assumption of the parasocial contact hypothesis-that a salient out-group identity allows effects to generalize beyond one individual to the outgroup as a whole. Our survey experiment demonstrates that primes emphasizing Salah's Muslim identity boosted the expression of tolerant opinions of Islam among Liverpool F.C. fans.

Our work builds upon prior research literature in three key ways. First, we provide causally identified, real-world evidence in support of the parasocial contact hypothesis. Existing studies primarily rely on correlational evidence from surveys-showing that those who consume media portraying minority group members have lower levels of prejudice - or from laboratory experiments on nonrepresentative populations. The first research strategy could suffer from reverse causality if people who already have low levels of prejudice choose to consume media portraying out-group members. The second research strategy, while solving the internal validity problems presented by correlational studies, is limited in its external validity. The artificial laboratory environment may generate larger effects than would be observed in more naturalistic settings, and undergraduate students may be particularly receptive to positive portrayals of out-group members. By contrast, our research design - which leverages differential exposure to the celebrity across different subsets of the British public-overcomes the internal validity problem. Additionally, the fact that we study real-life exposure, outside of an artificial experimental context, provides greater external validity.

Second, existing studies focus on self-reported measures of prejudice and behavior, often measured shortly after exposure to experimental manipulation. While these attitudinal measures are undoubtedly important, prior research leaves open the question of whether the effects extend to real-world behavior. Of the three studies we conduct here, two focus on behavioral outcomes that are measured by naturally occurring administrative and digital trace data rather than on self-reported measures. We therefore contribute evidence that parasocial contact can change behaviors as well as attitudes.

More broadly, our work contributes to a large literature in political communication documenting the effects of mass media on political attitudes. Political communication scholars have long been concerned with the effect that media portrayal of minorities-especially in the news-has on political attitudes. Experiments have shown that the way the media portray minority groups in the U.S. can shift people's attribution of responsibility for social issues, their evaluations of political candidates, and their policy attitudes (e.g., Gilliam and Iyengar 2000; Iyengar 1996; Valentino 1999). We add to this literature by showing that exposure to minorities in nonpolitical media can also influence attitudes and behavior. We hope that future work can adapt a similar research design to explore the influence of other public figures from minority groups on prejudice and assess the underlying mechanisms through which parasocial contact can shape prejudice. Such work will help us to better evaluate the scope conditions of the Salah effect and potentially offer new avenues for building social cohesion around the globe, especially where traditional contact across group lines is difficult to achieve.

\section{SUPPLEMENTARY MATERIALS}

To view supplementary material for this article, please visit http://dx.doi.org/10.1017/S0003055421000423.

\section{DATA AVAILABILITY STATEMENT}

Data and code to replicate the results in this paper are posted at the American Political Science Review Dataverse: https://doi.org/10.7910/DVN/2JKWNS.

\section{ACKNOWLEDGMENTS}

For helpful feedback, we thank Vincent Bauer, Lisa Blaydes, Andrew Brooks, Simon Ejdemyr, Jens 
Hainmueller, Niklas Harder, David Laitin, Hans Lueders, Rachel Myrick, Laura Paler, Christiana Parreira, James Tozer, Matthew Tyler, Elisabeth van Lieshout, Jeremy Weinstein, Robb Willer, Scott Williamson, seminar participants at the Immigration Policy Lab, and the APSR Editors and reviewers. We thank Toby Nowacki for replicating our empirical analyses. We are grateful to Yiqing Xu and Licheng Liu for advice on the gsynth package and to YouGov for sharing data.

\section{FUNDING STATEMENT}

This project was generously funded by the Institute for Research in the Social Sciences (IRiSS) at Stanford University and by the Immigration Policy Lab (IPL).

\section{REFERENCES}

Abadie, Alberto, Alexis Diamond, and Jens Hainmueller. 2010. "Synthetic Control Methods for Comparative Case Studies : Estimating the Effect of California's Tobacco Control Program." Journal of the American Statistical Association 105 (490): 493-505.

Aberson, Christopher L. 2015. "Positive Intergroup Contact, Negative Intergroup Contact, and Threat as Predictors of Cognitive and Affective Dimensions of Prejudice." Group Processes \& Intergroup Relations 18 (6): 743-60.

Abrams, Jessica R., Karen J. McGaughey, and Hannah Haghighat. 2018. "Attitudes toward Muslims: A Test of the Parasocial Contact Hypothesis and Contact Theory." Journal of Intercultural Communication Research 47 (4): 276-92.

Adida, Claire L., Adeline Lo, and Melina R. Platas. 2018. "Perspective Taking Can Promote Short-term Inclusionary Behavior toward Syrian Refugees." Proceedings of the National Academy of Sciences 115 (38): 9521-26.

Alrababa'h, Ala', William Marble, Salma Mousa, and Alexandra Siegel. 2021. "Replication Data for: Can Exposure to Celebrities Reduce Prejudice? The Effect of Mohamed Salah on Islamophobic Behaviors and Attitudes." Harvard Dataverse. Dataset. https:// doi.org/10.7910/DVN/2JKWNS.

Al Ramiah, Ananthi, and Miles Hewstone. 2013. "Intergroup Contact as a Tool for Reducing, Resolving, and Preventing Intergroup Conflict: Evidence, Limitations, and Potential." American Psychologist 68 (7): 527-42.

Al-Sayyad, Yasmine. 2018. "Liverpool F.C.'s Mohamed Salah, an Arab Muslim Sports Star Subtly Confronting Racism and Islamophobia." New Yorker, May 25, https://www. newyorker.com/sports/sporting-scene/liverpool-fcs-mohamedsalah-an-arab-muslim-sports-star-subtly-confronting-racism-andislamophobia.

Allport, Gordon W. 1954. The Nature of Prejudice, 25th edition. Cambridge, MA: Perseus Books.

Athey, Susan, Mohsen Bayati, Nikolay Doudchenko, Guido Imbens, and Khashayar Khosravi. 2021. "Matrix Completion Methods for Causal Panel Data Models." Working Paper. https://arxiv.org/pdf/ 1710.10251.pdf.

Awan, Imran, and Irene Zempi. 2016. "The Affinity between Online and Offline Anti-Muslim Hate Crime: Dynamics and Impacts." Aggression and Violent Behavior 27: 1-8.

Barlow, Fiona Kate, Stefania Paolini, Anne Pedersen, Matthew J Hornsey, Helena R. M. Radke, Jake Harwood, Mark Rubin, and Chris G. Sibley. 2012. "The Contact Caveat: Negative Contact Predicts Increased Prejudice More Than Positive Contact Predicts Reduced Prejudice." Personality and Social Psychology Bulletin 38 (12): 1629-43.

Barnhardt, Sharon. 2009. "Near and Dear? Evaluating the Impact of Neighbor Diversity on Inter-religious Attitudes." Unpublished Working Paper. http://research.economics.unsw.edu.au/gbose/ DevWorkshop/papers/Barnhardt_near_and_dear_paper.pdf.
Bascombe, Chris. 2019. "Jurgen Klopp Full of Praise for Mohamed Salah after Time Magazine Recognition: 'It's An Important Statement For The World."” Telegraph, April 19. https:// www.telegraph.co.uk/football/2019/04/19/jurgen-klopp-fullpraise-mohamed-salah-time-magazine-recognition/.

BBC. 2016. "EU Referendum Results.” Technical Report. https:// liverpool.gov.uk/council/key-statistics-and-data/census/censussummary/.

BBC News. 2014. "One Third of Britons'Admit Being Racially Prejudiced.” May 28, https://www.bbc.com/news/uk-27599401.

Bond, Bradley J. 2020. "The Development and Influence of Parasocial Relationships with Television Characters: A Longitudinal Experimental Test of Prejudice Reduction through Parasocial Contact." Communication Research 48 (4): 573-93.

Borden, Sam. 2014. "The Friendly Derby? Well, Everton-Liverpool Is Friendlier." The New York Times, January 28. https:/ www.nytimes.com/2014/01/28/sports/soccer/the-friendly-derbywell-everton-liverpool-is-friendlier.html.

Broockman, David, and Joshua Kalla. 2016. "Durably Reducing Transphobia: A Field Experiment on Door-to-Door Canvassing." Science 352 (6282): 220-24

Brown, Rupert, and Miles Hewstone. 2005. “An Integrative Theory of Intergroup Contact." Advances in Experimental Social Psychology 37 (37): 255-43.

Brown, William J., and Michael D. Basil. 1995. "Media Celebrities and Public Health: Responses to 'Magic' Johnson's HIV Disclosure and Its Impact on AIDS Risk and High-risk Behaviors." Health Communication 7 (4): 345-70.

Buchanan, Larry, Quoctrung Bui, and Jugal K. Patel. 2020. "Black Lives Matter May Be the Largest Movement in U.S. History." The New York Times, July 3. https://www.nytimes.com/interactive/ 2020/07/03/us/george-floyd-protests-crowd-size.html.

Burns, Justine, Lucia Corno, and Eliana La Ferrara. 2015. "Interaction, Prejudice and Performance: Evidence from South Africa." Unpublished Working Paper. https://bit.ly/30T51z1.

Carrell, Scott E., Mark Hoekstra, and James E. West. 2015. "The Impact of Intergroup Contact on Racial Attitudes and Revealed Preferences." National Bureau of Economic Research. Working Paper No. w20940. http://www.nber.org/papers/w20940.

Dovidio, John F., Angelika Love, Fabian M. H. Schellhaas, and Miles Hewstone. 2017. "Reducing Intergroup Bias through Intergroup Contact: Twenty Years of Progress and Future Directions." Group Processes \& Intergroup Relations 20 (5): 606-20.

Elahi, Farah, and Omar Khan. 2017. "Islamophobia: Still a Challenge for Us All." Runnymede Trust. https://bit.ly/2K9SXDI.

Enos, Ryan D. 2017. The Space between Us: Social Geography and Politics. Cambridge: Cambridge University Press.

Ensari, Nurcan, and Norman Miller. 2002. "The Out-group Must Not Be So Bad After All: The Effects of Disclosure, Typicality, and Salience on Intergroup Bias." Journal of Personality and Social Psychology 83 (2): 313-29.

Foos, Florian, and Daniel Bischof. 2018. "Can the Tabloid Media Create Eurosceptic Attitudes? A Quasiexperiment on Media Influence in England." Working Paper. http://www.florianfoos.net/ resources/Foos_Bischof_Hillsborough.pdf.

Fujioka, Yuki. 1999. "Television Portrayals and African-American Stereotypes: Examination of Television Effects When Direct Contact Is Lacking." Journalism \& Mass Communication Quarterly 76 (1): 52-75.

Gilliam, Franklin D., and Shanto Iyengar. 2000. "Prime Suspects: The Influence of Local Television News on the Viewing Public." American Journal of Political Science 44 (3): 560-73.

Goodwin, Matthew, and Caitlin Milazzo. 2017. "Taking Back Control? Investigating the Role of Immigration in the 2016 Vote for Brexit." The British Journal of Politics and International Relations 19 (3): 450-64.

Hainmueller, Jens, Daniel J. Hopkins, and Teppei Yamamoto. 2014. "Causal Inference in Conjoint Analysis: Understanding Multidimensional Choices via Stated Preference Experiments." Political Analysis 22: 1-30.

Harvard, Sarah. 2017. "Why Doesn't the Muslim Community Look Up to Its Black Celebrities?" The Washington Post, September 20. https://www.washingtonpost.com/news/acts-of-faith/ wp/2017/09/20/why-doesnt-the-muslim-community-look-up-to-itsblack-celebrities/?noredirect=on. 
Home Office. 2012. "Hate Crimes, England and Wales 2011 to 2012." Technical Report. https:/www.gov.uk/government/publications/ hate-crimes-england-and-wales-2011-to-2012--2/hate-crimesengland-and-wales-2011-to-2012.

Hopkins, Daniel J. 2010. "Politicized Places: Explaining Where and When Immigrants Provoke Local Opposition.” American Political science Review 104 (1): 40-60.

Iyengar, Shanto. 1996. "Framing Responsibility for Social Issues." The ANNALS of the American Academy of Political and Social Science 546 (1): 59-70.

Joyce, Nick, and Jake Harwood. 2014. "Improving Intergroup Attitudes through Televised Vicarious Intergroup Contact: Social Cognitive Processing of Ingroup and Outgroup Information." Communication Research 41 (5): 627-43.

Khattab, Nabil, and Ron Johnston. 2015. "Ethno-religious Identities and Persisting Penalties in the UK Labor Market." The Social Science Journal 52 (4): 490-502.

Liverpool City Council. 2011. "Census Summary.” Technical Report. https://liverpool.gov.uk/council/key-statistics-and-data/census/ census-summary/.

Lowe, Matt. 2017. "Types of Contact: A Field Experiment on Collaborative and Adversarial Caste Integration." MIT. Working Paper.

Lukaku, Romelu. 2018. "I've Got Some Things to Say." The Players Tribune, June 18. https://www.theplayerstribune.com/en-us/ articles/romelu-lukaku-ive-got-some-things-to-say.

Madziva, Roda. 2018. "'Your Name Does Not Tick the Box': The Intertwining of Names, Bodies, Religion and Nationality in the Construction of Identity within the UK Asylum System." Ethnic and Racial Studies 41 (5): 938-57.

Magdy, Walid, Kareem Darwish, and Norah Abokhodair. 2015. "Quantifying Public Response towards Islam on Twitter after Paris Attacks." Unpublished Manuscript. https://arxiv.org/abs/1512.04570.

Mastro, Dana E., and Linda R. Tropp. 2004. "The Effects of Interracial Contact, Attitudes, and Stereotypical Portrayals on Evaluations of Black Television Sitcom Characters."

Communication Research Reports 21 (2): 119-29.

McLeod, Maurice. 2013. "Theresa May's Immigration Bill Is a Valuable Tool for Racist Landlords." The Guardian, October 15. https:/www.theguardian.com/commentisfree/2013/oct/15/theresamay-immigration-bill-racist-landlords.

Miller, Patrick R., Andrew R. Flores, Donald P. Haider-Markel, Daniel C. Lewis, Barry Tadlock, and Jami K. Taylor. 2020. "The Politics of Being "Cait": Caitlyn Jenner, Transphobia, and Parasocial Contact Effects on Transgender-related Political Attitudes." American Politics Research 48 (5): 622-34.

Milly, Williamson, and Gholam Khiabany. 2010. "UK: The Veil and the Politics of Racism." Race \& Class 52 (2): 85-96.

Monks, Kieron. 2018. "Mohamed Salah's Greatest Legacy May Be off the Pitch." Middle East Eye, May 28. https://www.middle easteye.net/opinion/mohamed-salahs-greatest-legacy-may-bepitch.

Moore, Kelly, Paul Mason, and Justin Matthew Wren Lewis. 2008. "Images of Islam in the UK: The Representation of British Muslims in the National Print News Media 2000-2008.” Working Paper. http://orca.cf.ac.uk/id/eprint/53005.

Office for National Statistics. 2019. "Population of the UK by Country of Birth and Nationality." https://www.ons.gov.uk/people populationandcommunity/populationandmigration/ internationalmigration/datasets/populationoftheunited kingdombycountryofbirthandnationality./

Ortiz, Michelle, and Jake Harwood. 2007. "A Social Cognitive Theory Approach to the Effects of Mediated Intergroup Contact on Intergroup Attitudes." Journal of Broadcasting \& Electronic Media 51 (4): 615-31.

Paluck, Elizabeth Levy, Seth Green, and Donald P. Green. 2019. "The Contact Hypothesis Re-evaluated." Behavioural Public Policy 3 (2): 129-58.

Paolini, Stefania, Jake Harwood, and Mark Rubin. 2010. "Negative Intergroup Contact Makes Group Memberships Salient: Explaining Why Intergroup Conflict Endures." Personality and Social Psychology Bulletin 36 (12): 1723-38.

Park, Sung-Yeon. 2012. "Mediated Intergroup Contact: Concept Explication, Synthesis, and Application." Mass Communication and Society 15: 136-59.
Pettigrew, Thomas F. 1998. "Intergroup Contact Theory." Annual Review of Psychology 49: 65-85.

Pettigrew, Thomas F., and Linda R. Tropp. 2006. "A Meta-analytic Test of Intergroup Contact Theory." Journal of Personality and Social Psychology 90 (5): 751-83.

Qurashi, Fahid. 2018. "The Prevent Strategy and the UK 'War on Terror': Embedding Infrastructures of Surveillance in Muslim Communities." Palgrave Communication 4 (1): 1-13.

Ramasubramanian, Srividya. 2013. "Intergroup Contact, Media Exposure, and Racial Attitudes." Journal of Intercultural Communication Research 42 (1): 54-72.

Ramasubramanian, Srividya. 2015. "Using Celebrity News Stories to Effectively Reduce Racial/Ethnic Prejudice.” Journal of Social Issues 71 (1): 123-38.

Ramasubramanian, Srividya, and Chantrey J. Murphy. 2014. Experimental Studies of Media Stereotyping Effects. In Laboratory Experiments in the Social Sciences, 2 edition, eds. Murray Webster Jr. and Jane Sell, 385-402. Cambridge, MA: Academic Press.

Rao, Gautam. 2019. "Familiarity Does Not Breed Contempt: Diversity, Discrimination and Generosity in Delhi Schools." American Economic Review 109 (3): 774-809.

Reid, Jason. 2017. "We May Have Seen the Last of Colin Kaepernick in the NFL." The Undefeated, June 7. https://theundefeated.com/ features/we-may-have-seen-the-last-of-colin-kaepernick-in-the$\mathrm{nfl} /$.

Reyes Jr., Ruben E. 2018. "Queer Eye for the Small-minded Guy." The Harvard Crimson, July 25. https://www.thecrimson.com/ column/pop-cultural/article/2018/7/25/reyes-queer-eye/.

Schiappa, Edward, Peter B. Gregg, and Dean E. Hewes. 2005. "The Parasocial Contact Hypothesis." Communication Monographs 72 (1): 92-115.

Schiappa, Edward, Peter B. Gregg, and Dean E. Hewes. 2006. "Can One TV Show Make a Difference? A Will \& Grace and the Parasocial Contact Hypothesis." Journal of Homosexuality 51 (4): 15-37.

Sheridan, Lorraine P. 2006. "Islamophobia Pre-and Post-September 11th, 2001." Journal of Interpersonal Violence 21 (3): 317-36.

Simonivitz, Gabor, Gabor Kezdi, and Peter Kardos. 2018. "Seeing the World through the Other's Eye: An Online Intervention Reducing Ethnic Prejudice." American Political Science Review 112 (1): 186-93.

Smith, Rory, and Tariq Panja. 2020. "The Erasure of Mesut Ozil." The New York Times, October 26. https://www.nytimes.com/ 2020/10/26/sports/soccer/mesut-ozil-arsenal-china.html.

Sønderskov, Kim Mannemar, and Jens Peter Frølund Thomsen. 2015. "Contextualizing Intergroup Contact: Do Political Party Cues Enhance Contact Effects?" Social Psychology Quarterly 78 (1): 49-76.

Stanley-Becker, Isaac. 2018. "Mesut Ozil: World Cup Player Says He Is 'A German When We Win' but 'An Immigrant When We Lose,' Quits National Team.” The Washington Post, July, 7. https:// www.washingtonpost.com/news/morning-mix/wp/2018/07/23/ quitting-national-team-world-cup-player-says-he-is-a-germanwhen-we-win-but-an-immigrant-when-we-lose/.

Stevenson, Jacqueline, Sean Demack, Bernie Stiell, Muna Abdi, Lisa Clarkson, Farhana Ghaffar, and Shaima Hassan. 2017. "The Social Mobility Challenges Faced by Young Muslims." Social Mobility Commission. https://assets.publishing.service.gov.uk/government/ uploads/system/uploads/attachment_data/file/642220/Young_ Muslims_SMC.pdf.

Streeter, Kurt. 2020. "Kneeling, Fiercely Debated in the N.F.L., Resonates in Protests." The New York Times, June 5. https:// www.nytimes.com/2020/06/05/sports/football/george-floydkaepernick-kneeling-nfl-protests.html.

Tell Mama. 2017. "Beyond the Incident: Outcomes for Victims of Anti-Muslim Prejudice.” Technical Report. https://

tellmamauk.org/wp-content/uploads/2018/07/Tell-MAMAReport-2017.pdf.

The National. 2018. "Footballer Mo Salah is tackling Islamophobia Head-on.” April 23. https://www.thenationalnews.com/opinion/ editorial/footballer-mo-salah-is-tackling-islamophobia-head-on1.724010 .

Thomas, Andi. 2018. "Soccer Star Mo Salah's Massive Popularity Is Changing Perceptions of Muslims in the UK." Vox.com, June 15. 
https:/www.vox.com/world/2018/6/15/17433822/mo-salahliverpool-injury-egypt-2018-world-cup-muslim-islam.

Valentino, Nicholas A. 1999. "Crime News and the Priming of Racial Attitudes during Evaluations of the President." Public Opinion Quarterly 63 (3): 293-320.

Vezzali, Loris, Miles Hewstone, Dora Capozza, Dino Giovannini, and Ralf Wolfer. 2014. "Improving Intergroup Relations with Extended and Vicarious Forms of Indirect Contact." European Review of Social Psychology 25 (1): 314-89.

Williams, Pat, and Mike Sielski. 2004. How to Be Like Jackie Robinson. Deerfield Beach, FL: Health Communications.

Wiseman, Eva. 2018. "Nadiya Hussain: 'This Is More Than a Job: It's Important to Be Out There."” The Guardian, December 16. https://www.theguardian.com/food/2018/dec/16/nadiya-hussainbake-off-winner-this-is-more-than-a-job.

Wong, Norman C. H., Kathryn L. Lookadoo, and Gwendelyn S. Nisbett. 2017. "I'm Demi and I Have Bipolar Disorder": Effect of Parasocial Contact on Reducing Stigma toward People with Bipolar Disorder.” Communication Studies 68 (3): 314-33.

Wright, Stephen C., Arthur Aron, Tracy McLaughlin-Volpe, and Stacy A. Ropp. 1997. "The Extended Contact Effect: Knowledge of Cross-group Friendships and Prejudice." Journal of Personality and Social Psychology 73 (1): 73-90.

$\mathrm{Xu}$, Yiqing, and Licheng Liu. 2018. gsynth: Generalized Synthetic Control Method. R package version 1.0.9. https://CRAN.Rproject.org $/$ package=gsynth. 